\title{
Results of a Survey to Benchmark Canadian Health Facility Libraries ${ }^{1}$
}

\author{
Ada Ducas, Lisa Demczuk, and Kerry Macdonald
}

\begin{abstract}
Introduction: A benchmarking survey of Canadian health facility libraries was conducted to provide statistical data to support health librarians in the management of their libraries. The objectives were to determine the status of hospital libraries in Canada and to evaluate whether libraries meet the 2006 CHLA/ABSC Standards for Library and Information Services in Canadian Healthcare Facilities. Methods: An online survey of 63 questions, with headings of institutional profile, administration, staffing, environment, resources, and services, was created and distributed to 250 heads of hospital libraries and to Canadian library email listservs. Results: Many libraries are meeting some aspects of the Standards for administration and organization, management, traditional promotion, and accessibility. Areas of improvement include services, nontraditional promotion, library environment, and staffing. Discussion: There are no current benchmarking data available for Canadian hospital libraries and there have been many political, economic, and technological changes in past years that have had a substantial impact on libraries. Anecdotal data suggest that librarians have responded to these changes through library closures, mergers, consortial affiliations, and modifications to services. Librarians will be able to use the collected data to compare services, establish best practices, make management decisions, and prepare self-studies for accreditation purposes.
\end{abstract}

\section{Introduction}

Today's health sciences libraries experience constant and rapid evolution. During times of change, library management decision-making, strategic planning, and value assessment need to rely on the currency of data and situational awareness provided by library status and benchmarking information. The last full snapshot of the status of Canadian health sciences libraries was provided in 1997 [1], followed more recently by a report on the Canadian subset of benchmarking data from the 20072008 Medical Library Association Benchmarking Survey [2]. Recently, other jurisdictions such as Ireland [3] and Australia [4] have provided reports on the status of health libraries for the purposes of advocacy, standard development, and setting future directions. Standards of practice as developed by professional library associations are closely tied to information about library status and benchmarking data, and they help to guide library operations and management activities [5]. A close relationship between benchmarking data and standard development is needed both to ensure relevancy of standards and to measure the ability of libraries to meet the standards. The current standards for Canadian health sciences libraries were produced in 2006 [6], but rapid changes in library environments could necessitate their updating to support current and future practice. It is with these factors in mind that we decided to conduct a benchmarking survey of Canadian health facility libraries. The objectives were to $(i)$ gain an understanding of the status of Canadian health facility libraries and (ii) to determine whether these libraries were meeting the 2006 CHLA/ABSC Standards for Library and Information Services in Canadian Healthcare Facilities. This paper reports on the methodology and outcomes of the survey.

\section{Background}

Within the last $12-15$ years in particular, health sciences libraries have experienced transformations in resource type and access, funding and staffing levels, and client expectations and service delivery. The recent health sciences library literature explores many facets of this rapid and increasing change. Advances in technology have brought both new opportunities and new demands to health sciences libraries as seen with mobile resources [7,8] and web 2.0 and social networking $[9,10]$. Library staffing and

Ada Ducas ${ }^{2}$, Neil John Maclean Library, University of Manitoba, 770 Bannatyne Avenue, Winnipeg, MB R3E 0 W3.

Lisa Demczuk. Elizabeth Dafoe Library, University of Manitoba, 25 Chancellor's Circle, Winnipeg, MB R3T 2 N2.

Kerry Macdonald. Carolyn Sifton - Helene Fuld Library, University of Manitoba, 409 Taché Avenue, Winnipeg, MB R2H 2A6.

${ }^{1}$ This article has been peer reviewed.

2Corresponding author (e-mail: Ada.Ducas@umanitoba.ca) 
space have been affected by fluctuating budgets and shifts to predominantly electronic resources and collections [1113]. As indicated in Bayley and McKibbon's [14] brief report for International trends in health science librarianship, Canadian librarians have experienced rising expectations for service delivery and involvement in user education and research support at the same time as budgets have been decreasing, an experience that is mirrored in international health libraries [15]. Assessment of services and demonstration of value is increasingly a concern for health librarians as shown by studies on the value and impact of information services on patient care by Marshall et. al. [16] and the reporting of the Canadian data within that study [17]. The recent literature also explores new roles for health sciences librarians, including the clinical informationist role [18-20] and a focus on the expanding potential of the clinical librarian in expert searching, teaching, content management, and patient advocacy [21]. Other role changes and expansions are documented in a recent systematic review [22] including hospital librarian participation in multi-disciplinary teams throughout the organization [23], reflecting the trend of liaison relationships, and the embedded librarianship model [24]. The Medical Library Association's Vital Pathways: the Hospital Libraries Project [25] makes it evident that health sciences librarians need to identify and fully embrace current and future roles that will support the parent organization's goals [26].

\section{Methods}

An online survey was created using FluidSurveys, which was chosen for its multi-lingual capabilities and its Canadian server data storage. The survey consisted of 63 questions under the headings of institutional profile, administration, staffing, services, resources, and environment, which corresponded to the CHLA/ABSC standards. The development of the survey questions was also informed by the categories on the Medical Library Association's Benchmarking Data Worksheet for the MLA Benchmarking Survey conducted in 2007 [27]. The survey was offered in English and French and can be viewed in the supplementary files and (or) online at http:// tinyurl.com/benchmarkingsurveys. Ethics approval was obtained from the University of Manitoba Health Ethics Review Board. A Microsoft Excel contact list of hospitals and healthcare institutions was created using DOCLINE, HLWIKI [28], and the CHLA/ABSC institutional member list. Entries were cross-checked and the list supplemented using the Internet and the print directory Libraries Canada [29].

The survey was piloted in six health facility libraries in three provinces in September 2012. Edits to the survey questions and design were made based on the feedback received. The final email survey was sent to 250 entries in the contact list, including heads of libraries or, if this information was unavailable, to generic library email addresses. An invitation to complete the survey was also sent out over CANMEDLIB, the CHLA/ABSC email listserv, and to various provincial health library association member lists. Completion of the survey was voluntary and all information received was kept confidential. The survey data were evaluated using descriptive data analysis.

\section{Results}

\section{Demographic overview of respondents}

The total number of responses received was 168 , for an estimated response rate of $67 \%$ based on the 250 distributed surveys. Survey responses were also received from the listserv invitations, so this response rate is an estimate only. Answering questions was not mandatory and some respondents chose not to answer all questions resulting in a $46 \%$ completion rate. Representation was present from eight out of ten Canadian provinces with Ontario $(32 \%$, $N=25 / 77)$ and Quebec $(27 \%, N=21 / 77)$ having the largest number of responses. No survey responses were received from Newfoundland and Labrador, Prince Edward Island, or the Territories. Hospital libraries accounted for $81 \%(N=62 / 77)$ of the responses with over half of respondents from acute care facilities. The remaining responses predominantly fell under the areas of long term care, government, academic, and virtual or embedded services.

\section{Survey results}

The major objective of this study was to determine if Canadian health facility libraries are meeting the 2006 CHLA/ABSC Standards for Library and Information Services in Canadian Healthcare Facilities. The secondary objective was to determine the status of health facility libraries in Canada, a goal that was largely met by looking at the survey results in relation to the Standards. The survey data could also provide evidence of need for changes to the standards. The CHLA/ABSC Standards focus on nine key areas in libraries: administration and organization, management, staffing, services, resources, promotion, legislation and compliance, accessibility, and environment. Standard 7, legislation and compliance, was outside the realm of this study and is therefore not addressed in this paper. The key aspects of all other standards are discussed below in relation to the relevant survey questions and findings. The full data and findings for the study will reside on the CHLA/ABSC website.

\section{Standard 1. Administration and Organization}

The library has its own budget and the librarian reports to Senior Management.

The intent of Standard 1 is to ensure that libraries are well positioned to provide education and evidence-based information to library users. "Department status facilitates this process and enhances the library's ability to work with all areas within the hospital or health region" [6]. Ninetyeight percent $(N=47 / 48)$ of survey respondents reported that their library is considered a separate department with its own budget, meaning that participating libraries meet the requirements of this Standard. In addition, $62 \%(N=$ 48/77) of respondents said their library was administered by the healthcare facility in which it resided, with most of the libraries reporting to Education Services (Figure 1). 
Fig. 1. In the healthcare facility's organization chart, to which area or department does the library report? ${ }^{*}$ Other responses included knowledge innovation, research department, organizational development, and earning institute.

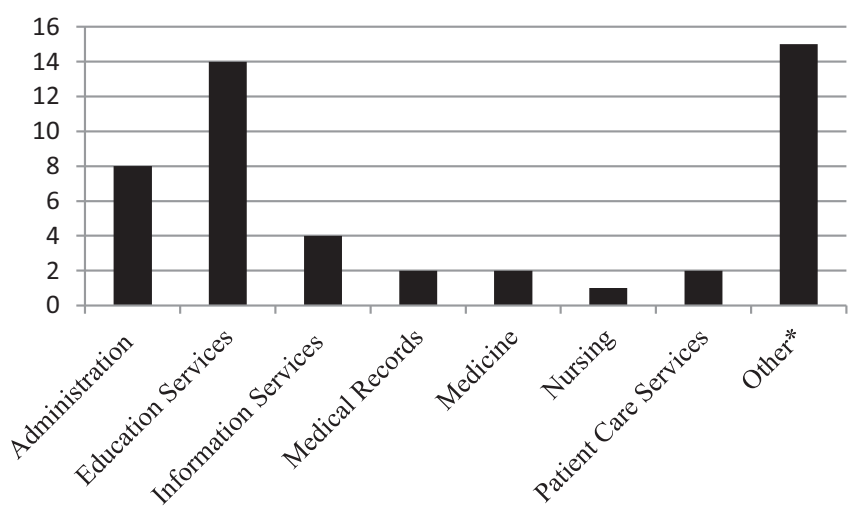

Another $16 \%(N=12 / 77)$ of respondents reported that their library was administered by an academic library system.

\section{Standard 2. Management}

The library and information service is managed by a professional librarian with an ALA accredited Master's degree program.

Standard 2 places emphasis on the competencies of professional librarians as key to serving the clientele's information needs. The survey results showed that a professional librarian holding a master's degree managed $70 \%(N=54 / 77)$ of libraries. Thirteen percent of libraries $(N=10 / 77)$ were managed by a library technician and $8 \%$ $(N=6 / 77)$ by an individual with no library training. Nine percent $(N=7 / 77)$ of respondents indicated various other training, including Human resources training, a Bachelor's degree with a focus in library studies, and long-term service.

\section{Standard 3. Staffing}

The library and information service is staffed according to the MLA staffing formula of total institution FTE/700.

The Standards recommend following the Medical Library Association staffing formula that suggests a minimum of 1 full-time equivalent (FTE) library staff member per 700 FTE health institution staff. Further recommendations are given for the ratio of technical employees to librarian for a library staff of 1 FTE, 1.0-3.0 FTE, and greater than 3.0 FTE. Staffing must include at least a parttime librarian when there is 1 FTE or less in a library [30]. Twenty percent $(N=14 / 69)$ of libraries did not employ a librarian with a Master's degree and thus did not meet this particular requirement. Of those libraries employing one or more librarians, $15 \%(N=8 / 55)$ did not meet the requirements of the staffing mix as outlined in the MLA staffing standards.

\section{Standard 4. Services}

The librarian conducts an ongoing assessment of the information services needs of the organization, and uses this assessment to develop and implement appropriate services to meet these needs and to maintain alignment with the organization's mission, vision, goals, and strategic plan.

Services provided by hospital libraries are addressed in Standard 4, with an emphasis on provision of expert searching, technology supporting electronic resource access, delivery of training in evidence-based searching, and document delivery. Health facility libraries continue to perform mediated literature searches $(94 \%, N=60 / 64)$ and teaching sessions $(86 \%, N=55 / 64)$ as part of their core services. Another core service, document delivery, is provided by all but one respondent library through membership in a reciprocal Interlibrary Loan network. In terms of technology to support access to resources, Wi-fi was available in $58 \%(N=44 / 76)$ of responding libraries and all libraries provided patron-accessible computers. The survey respondents met Standard 4 service requirements, but the intent of the standard also speaks to the necessity of ensuring users' needs are met by continual evaluation of service delivery. Fifteen percent $(N=11 / 75)$ of respondents said they do not routinely monitor or evaluate library services and 55\% $(N=41 / 75)$ occasionally use formal consultation to evaluate services (Table 1). Other means of evaluation included usage statistics, informal conversations and unsolicited feedback, and assessment by librarians. Two questions were asked about services or roles not covered by the Standard. The responses to question 38, which asked if libraries provided support for specific activities, showed only $43 \%(N=32 / 74)$ of respondents did not provide any support for institutionwide activities such as records and archives, website maintenance, audio-visual and room bookings. In addition, only $36 \%(N=23 / 73)$ of respondents indicated that librarians were not involved in liaison activities such as providing clinical or embedded librarian services, serving as members of research or other teams, councils and (or) committees, and teaching.

\section{Standard 5. Resources}

The library and information service provides knowledgebased resources that support all user information needs.

The survey results showed that the top electronic databases subscribed to by libraries were CINAHL,

Table 1. How are library services monitored or evaluated?

\begin{tabular}{lr}
\hline Monitoring method & No. (\%) \\
\hline Occasional formal user consultation & $41(55)$ \\
Key performance indicators & $22(29)$ \\
Regular formal user consultation & $18(24)$ \\
Formal framework of service standards & $4(5)$ \\
No routine monitoring/evaluation & $11(15)$ \\
I don't know & $0(0)$ \\
Other, please specify & $11(15)$
\end{tabular}

Note: Respondents could check all that applied; therefore, column totals do not equal $100 \%$. 
Cochrane Library, MEDLINE, and PsycINFO (Figure 2). Point of care resources were subscribed to at a much lesser extent than online article databases, with the most popular subscriptions being UpToDate, ACP Pier, and MDConsult (Figure 3). The most widely licensed drug resource was the e-CPS followed by Lexi-Comp (Figure 4).

Fig. 2. Which of the following electronic resources are purchased for your library? *Resources listed under "other" were mainly drug and point of care resources, which were asked in subsequent survey questions.

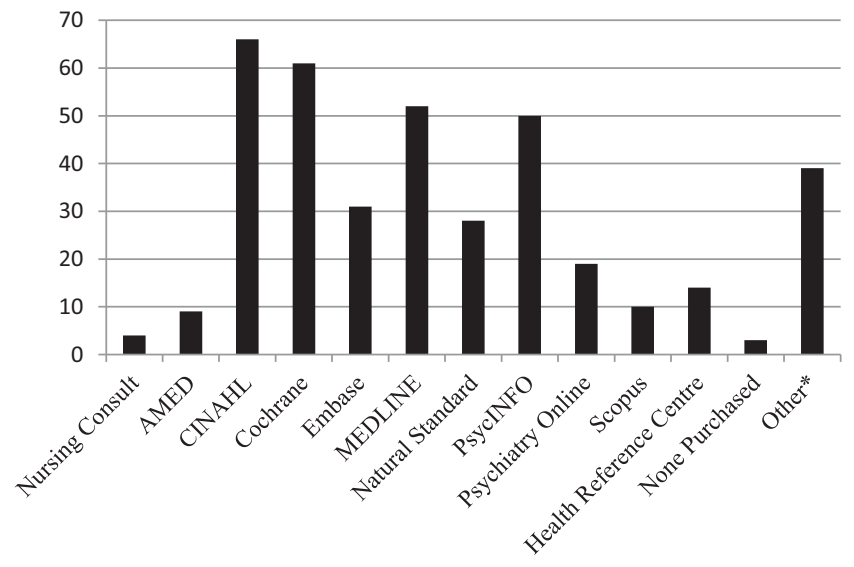

Fig. 3. Which of the following point of care resources are purchased for, or by, your library?

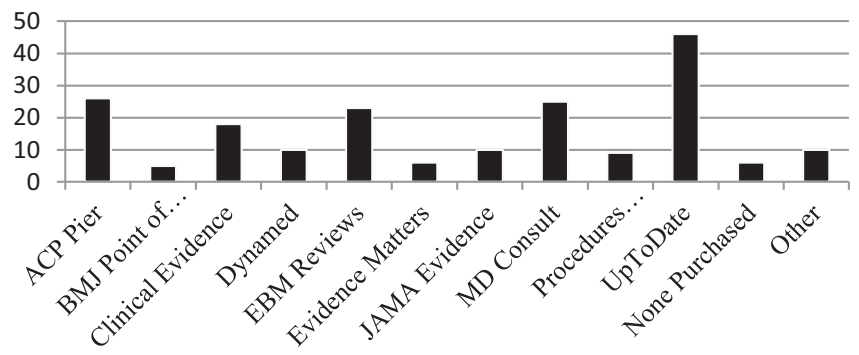

Fig. 4. Which of the following drug information resources are purchased for your library?

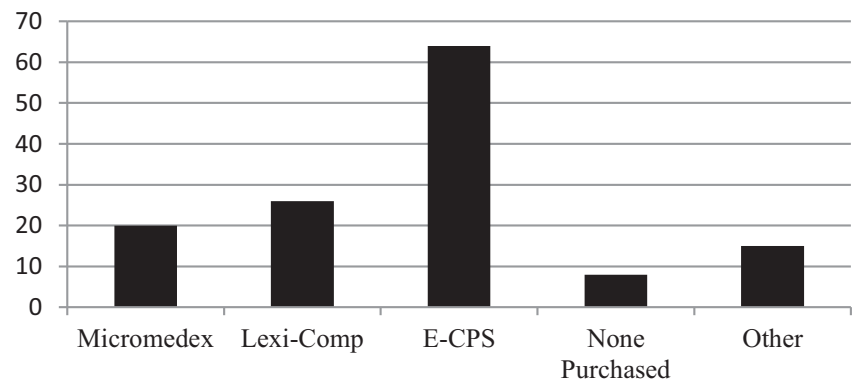

The provision of knowledge-based resources to support consumer health is also part of Standard 5. Twenty-seven percent $(N=20 / 73)$ of libraries do not provide health information to patients and families. Although over half of libraries $(56 \%, N=41 / 73)$ provided reference services to patients and families, only $40 \%(N=29 / 73)$ lent materials to this user group and $30 \%(N=22 / 73)$ offered patient brochures.

\section{Standard 6. Promotion}

The library and information service actively promotes knowledge-based information services to all primary client groups.

According to the survey results, library staff participated in or hosted the following promotional activities: displays $(56 \% . N=40 / 72)$, institutional events $(69 \%, N=50 / 72)$, institutional orientation $(60 \%, N=43 / 72)$, library week $(29 \%, N=21 / 72)$, and open houses $(32 \%, N=23 / 72)$. Common means of promoting the library included the library website $(71 \%, N=54 / 76)$, the institutional intranet $(70 \%, N=53 / 76)$, institutional newsletter $(62 \%, N=47 /$ $76)$, and presentations $(66 \%, N=50 / 76)$. Although social media is increasingly used for promotional purposes, the vast majority of respondents do not use social media tools like blogs, RSS Feeds, Twitter, or Facebook (Table 2). In a related question, many respondents indicated that they were unable to use social media tools such as Facebook $(48 \%, N=34 / 71)$ and Twitter $(40 \%, N=29 / 73)$ because their parent institution blocked usage. Library staff members appear to be actively promoting their libraries by engaging in traditional promotional activities.

\section{Standard 8. Accessibility}

Appropriate knowledge-based information resources are accessible 24 hours a day, 7 days a week.

Standard 8 establishes the necessity of ready access to information resources, including electronic access via internet or intranet and after-hours physical library access, to support patient-care decision-making at all times.

Table 2. In the past year, which of the following did you use to raise awareness of your library or its services?

\begin{tabular}{lc}
\hline Tool used & No. $(\%)$ \\
\hline Institution's public website & $29(38)$ \\
Institution's intranet site & $53(70)$ \\
Library's own website & $54(71)$ \\
Facebook & $4(5)$ \\
Twitter & $7(9)$ \\
Library newsletter & $21(28)$ \\
Institutional newsletter & $47(62)$ \\
Brochures or fact sheets & $37(49)$ \\
New books list & $47(62)$ \\
Annual report & $27(36)$ \\
Presentations & $50(66)$ \\
Not Applicable & $1(1)$ \\
Other & $11(14)$
\end{tabular}

Note: Respondents could check all that applied; therefore, column totals do not equal $100 \%$. 
The survey results found that almost all libraries provided staffed access to the library 30 hours per week or more and $64 \%(N=49 / 77)$ of respondents offered clients 24-hour physical access to the library. Most respondents indicated that the library's resources were accessible to users via the internet $(48 \%, N=36 / 75)$ and (or) their institution's intranet $(61 \%, N=46 / 75)$. Eight percent $(N=6 / 75)$ responded that their library's electronic resources could only be accessed from within the library. Results indicated that the majority of health facility libraries meet the standard for accessibility, but that there is room for improvement.

\section{Standard 9. Environment}

Physical space accommodates current and future (3-5 years) requirements, for networked computers, print collections, staff workspaces, as well as areas for quiet study and group meetings.

The majority of respondents were confident in their library's ability to accommodate space requirements for the next 5 years for computers, print collections, staff workspace, and quiet study space and thus meet Standard 5 (Figure 5).

Facilities for instruction and workshops are available for use by library services.

Fifty-seven percent $(N=43 / 76)$ of respondents felt they wouldn't be able to accommodate future requirements for group meeting space, which would include library instruction and workshops for small and large groups (Figure 5). Eighty-eight percent $(N=68 / 77)$, however, indicated they had access to instructional facilities within their parent institution. Space within the library itself for teaching, quiet study, and group space varied widely amongst respondents, with many libraries reporting zero seats for teaching purposes $(67 \%, N=44 / 66)$ or group study $(56 \%$, $N=38 / 68$ ). Accommodating groups is an aspect of the standard that the majority of health facility libraries fail to meet.

Fig. 5. Does your library space accomodate future (i.e., 5 years) requirements for:

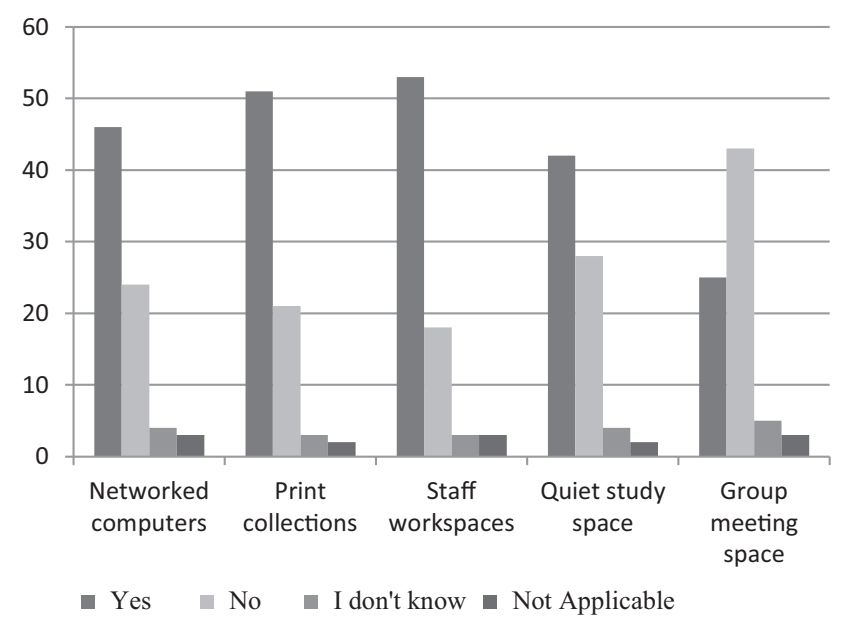

\section{Other findings of interest}

A number of survey questions attempted to capture changes over the past 5 years that have led to the current status of Canadian health facility libraries. Similar proportions of libraries experienced increases and decreases in the operational areas of staffing and budget, providing no clear trend for changes in these areas. Some notable changes in the area of library services included an increase in reference questions and literature searches (Table 3). In terms of collections, libraries have seen a decrease in print books and serials, with a corresponding increase in electronic books and serials (Table 4). With regards to changes of the physical library space, $42 \%(N=32 / 77)$ of libraries reported no change in the past 5 years (Table 5).

In concluding the survey, respondents were asked how satisfied they were with their library and the services they were providing. Seventy-one percent $(N=55 / 77)$ of respondents were satisfied or highly satisfied with their libraries and services (Figure 6).

\section{Discussion and recommendations}

The results of the survey provide a broad overview of Canadian health facility libraries. The survey did, however, have limitations in terms of construction, length, and responses. At 63 questions, the survey was lengthy and time-consuming to complete. Not every recipient of the survey responded, and of those who did, many did not answer all questions. This resulted in differing response rates for different questions, making it difficult to analyze the data and draw conclusions. Questions that asked respondents to report budget, expenditures, and statistics received the lowest response rates, perhaps indicating a challenge in keeping this kind of administrative data current and easily available for reporting. Budgetary questions also did not lend themselves well to library systems with multiple locations. For example, libraries reported having difficulty answering budgetary and collections questions given that funds and purchasing were centralized and managed in the main branch of their library system. For this reason, the construction of the survey was not well-suited to multi-site organizations or consortia. Also, because no question was asked about current practices around assessment of knowledge-based resource needs of healthcare staff for Standard 5, Resources, the authors are unable to comment on whether libraries are fulfilling these requirements. Due to the number of questions, the survey gathered a large amount of data, much of which is not reported in this paper. However, the data will reside with CHLA/ABSC and be made available to libraries wanting to compare their current situation with the data available.

In addition to providing a current snapshot of health facility libraries in Canada, the survey results reveal libraries' status in relation to the 2006 CHLA/ABSC Standards for Library and Information Services in Canadian Healthcare Facilities. The results indicate that libraries meet most, but not all, requirements in the current standards. Canadian health facility libraries are strongest in the standards of administration and organization, management, promotion, and accessibility. Based on 
Table 3. How has your library changed in the past five years?

\begin{tabular}{|c|c|c|c|c|c|}
\hline & $\begin{array}{c}\text { Increased, } \\
\text { no. }(\%)\end{array}$ & $\begin{array}{c}\text { Decreased, } \\
\text { no. }(\%)\end{array}$ & $\begin{array}{c}\text { Stayed the same, } \\
\text { no. }(\%)\end{array}$ & $\begin{array}{c}\text { Don't know, } \\
\text { no. }(\%)\end{array}$ & $\begin{array}{c}\text { Not applicable, } \\
\text { no. }(\%)\end{array}$ \\
\hline Staffing & $19(25)$ & $16(21)$ & $42(55)$ & $0(0)$ & $0(0)$ \\
\hline Document delivery/Interlibrary loan & $29(38)$ & $36(47)$ & $10(13)$ & $1(1)$ & $1(1)$ \\
\hline Reference questions & $40(52)$ & $12(16)$ & $23(30)$ & $2(3)$ & $0(0)$ \\
\hline Literature searches & $47(62)$ & $9(12)$ & $17(22)$ & $2(3)$ & $1(1)$ \\
\hline
\end{tabular}

Note: Respondents could check all that applied; therefore, column totals do not equal 100\%.

Table 4. How has your library collection changed in the past five years?

\begin{tabular}{lcccccc}
\hline & $\begin{array}{c}\text { Increased, } \\
\text { no. }(\%)\end{array}$ & $\begin{array}{c}\text { Decreased, } \\
\text { no. }(\%)\end{array}$ & $\begin{array}{c}\text { Stayed the same, } \\
\text { no. }(\%)\end{array}$ & $\begin{array}{c}\text { Don't collect, } \\
\text { no. }(\%)\end{array}$ & $\begin{array}{c}\text { Don't know, } \\
\text { no. }(\%)\end{array}$ & $\begin{array}{c}\text { Not applicable, } \\
\text { no. }(\%)\end{array}$ \\
\hline Books (print) & $9(12)$ & $38(49)$ & $25(32)$ & $0(0)$ & $4(5)$ & $1(1)$ \\
Books (electronic) & $47(61)$ & $3(4)$ & $14(18)$ & $3(4)$ & $0(0)$ & $10(13)$ \\
Serials (print) & $0(0)$ & $70(92)$ & $4(5)$ & $0(0)$ & $2(3)$ & $1(1)$ \\
Serials (electronic) & $55(71)$ & $7(9)$ & $7(9)$ & $10(13)$ & $2(3)$ & $2(3)$ \\
A/V Resources & $9(12)$ & $28(37)$ & $19(25)$ & $7(5)$ & $7(9)$ \\
\hline
\end{tabular}

Note: Respondents could check all that applied; therefore, column totals do not equal 100\%.

Table 5. Have the following changes occurred in your library in the past five years?

\begin{tabular}{lc}
\hline & No. $(\%)$ \\
\hline Library relocated & $20(26)$ \\
Library size decreased & $18(23)$ \\
Library size increased & $8(10)$ \\
Library merger & $4(5)$ \\
No changes & $32(42)$ \\
\hline
\end{tabular}

Note: Respondents could check all that applied; therefore, column totals do not equal $100 \%$.

Fig. 6. Rate how satisfied you are with your library and the services you provide.

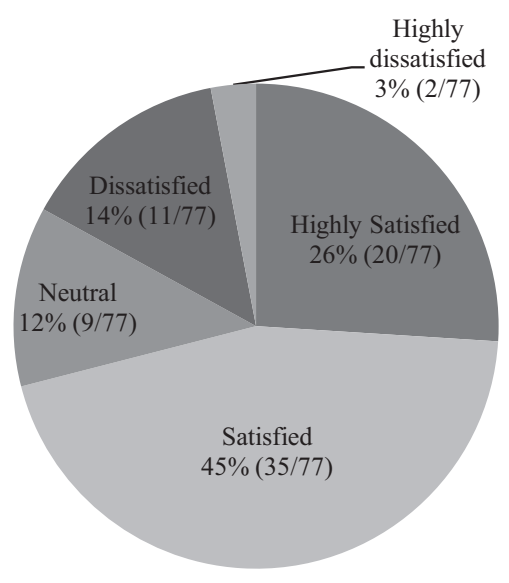

the survey results, Canadian health facility libraries appear to be well positioned to converse with senior health administration about the current and future requirements for library and information resources and services and they are actively promoting the library using traditional means of promotion. While health facility libraries meet the current standard for promotion by engaging in the activities suggested in the standard's guideline, the survey results also show room for improvement based on the low participation rate in social media-based promotion activities (Table 2). Key barriers identified to adopting social media based promotion activities are information technology rules and regulations and institution policy. This may change as the Canadian digital health movement advances, but fostering relationships and ensuring active involvement in health facility technology initiatives may assist librarians in having a say and being recognized as leaders in the areas of health information and data.

Other areas for improvement identified by the survey responses include the standards of services, library environment, and staffing. The results indicate that health facility libraries need to improve in the area of assessment of provided services (Table 1). Given increased expectations of accountability, health facility libraries will need to engage in more evaluation of services and resources to demonstrate value [31]. For the library environment, the majority of health facility libraries did not have adequate group study (Figure 5) or instructional space, a challenge given that only $10 \%(N=8 / 77)$ of libraries experienced size increases during the past 5 years (Table 5 ). To respond to the changing needs of users and institutions, health facility libraries can reinvent the existing library environment by gaining space from decreasingly used print collections and working with stakeholders to create dynamic, collaborative learning spaces [32]. Library staffing is another area that shows room for improvement with some health facility libraries not meeting the minimum staffing requirements as outlined in the Standards. As focus shifts to an emphasis on service and resource 
assessment and delivery, health facility libraries are increasingly expected to have staff in embedded positions and on multidisciplinary teams, delivering expert searching for systematic reviews and providing instruction and content management, among other new roles, all in support of organizational goals. It is recommended that the currently used MLA library staffing formula be examined for its relevance to contemporary practice. The staffing formula provides a minimum suggested staffing complement but recognizes that "enhanced services or services usually provided by other departments" will require additional staffing for the library [30]. The provision of what formerly may have been enhanced services is increasingly the new normal for health facility libraries. As the responses to survey questions about roles and services not covered by the Standards shows, the majority of libraries are involved in supporting institution-wide activities and engaged in liaison activities. Both of these types of services will impact library staff time and presence in the library and call into question the relevance of the current staffing recommendations which likely underestimate the number of staff needed.

The survey results have been reported in relation to the 2006 CHLA/ABSC Standards for Library and Information Services in Canadian Healthcare Facilities, in use now for nearly a decade. As discussed above, survey results demonstrate that libraries meet some but not all existing standards. Also at issue is the ability of the Standards to reflect and guide current practices of Canadian health facility libraries, and whether the current Standards need updating in light of the accelerated pace of transformation to health library practice. For example, survey results show that library staff are involved in a wide range of activities and services not considered by the current Standards. The Standards also do not reflect new methods of promoting library resources and services, such as the use of social media. Further, the Standards do not put sufficient emphasis on assessment, accountability, and demonstration of library value beyond the guidance provided in the services standard for assessment and evaluation of user information needs and services. In addition, although the Environment Standard recognizes the value of the library as place and refers to the libraries' need for quiet study and group meeting space, the Standards do not reflect the reality of vanishing print-based collections, reflected in the $49 \%$ decrease of print books and $92 \%$ decrease of print serials in the last 5 years (Table 4 ) or the need for inventive and collaborative spaces. Given these results, a revision of the Standards to reflect the current and evolving scope of practice for health libraries, especially in the new areas of service delivery and increasing expectations of accountability, is recommended. The reviewed literature and other documents such as the recent "Hospital Library \& Information Services: Scope of Practice" document produced by the Health Science Information Consortium of Toronto [33], the status report on health libraries from the Library Association of Ireland [3], and the value of health libraries report from the Australian Library and Information Association [4], support the survey findings that health libraries are experiencing changes in status, scope, and practice.

\section{Conclusion}

This paper reported on the methodology and outcomes of a survey designed to capture the current status of health facility libraries in Canada and to determine their success in meeting the 2006 CHLA/ABSC Standards for Library and Information Services in Canadian Healthcare Facilities. Canadian health facility libraries meet some, but not all, of the current standards, but while conducting this study and analyzing the results it became clear that an update of the Standards would be beneficial given the recent rapid evolution of library environments, scope of practice, and roles. Revising the Standards will help guide Canadian health facility libraries in the development and provision of the services most relevant to today's health care professional.

\section{Acknowledgements}

Statistical assistance was provided by Brenden Dufault, Statistician at the University of Manitoba. The authors wish to thank all survey respondents for their participation. The authors thank the board members of the Manitoba Association of Health Information Providers and CHLA/ABSC for their support. The authors recognize Stefania Zimarino and Jenna Baraschuk Modha, Library Assistants at the University of Manitoba, for their hard work in finalizing the database of library contacts.

\section{References}

1. Beckett GA. 1996 statistical survey of Canadian health sciences libraries: summary, results and observations. Bibl Med Can. 1997;18(3):95-8.

2. Logan P. Benchmarking: how do Canadian hospital libraries compare? J Can Health Libr Assoc. 2009 Dec;30(4):131-2.

3. Harrison J, Creaser C, Greenwood H. Irish health libraries: new directions. Report of the status of health librarianship and libraries in Ireland (SHELLI) [Internet]. Dublin: Library Association of Ireland, Health Sciences Library Group; 2011 [cited 2014 Nov 20]. Available from: http://www.hslg.ie/shelli/.

4. Health Libraries Inc. Questions of life and death: an investigation into the value of health library and information services in Australia. [Internet]. Australia: Health Libraries Inc.; 2012 [cited 2014 Nov 2]. Available from: http://www. alia.org.au/sites/default/files/documents/advocacy/HLI-ALIA ValuingHealthInformationServicesReport2012v2.pdf.

5. Funk CJ. Using standards to make your case: examples from the medical library community. New Libr World. 2008 May; 109(5):251-7.

6. Standards for Library and Information Services in Canadian Healthcare Facilities 2006. J Can Health Libr Assoc. 2007; 28(1):3-7. doi: 10.5596/c07-009.

7. Bushhousen E, Norton HF, Butson LC, Auten B, Jesano R, David D, Tennant MR. Smartphone use at a university health science center. Med Ref Serv Q. 2013;32(1):52-72.

8. Witman L. Hospital clinicians' iPad use: an interim report. Med Ref Serv Q. 2012;31(4):433-8. doi: 10.1080/02763869. 2012.724304 . 
9. Gardois P, Colombi N, Grillo G, Villanacci MC. Implementation of web 2.0 services in academic, medical and research libraries: a scoping review. Health Info Libr J. 2012 Jun; 29(2):90-109. doi: 10.1111/j.1471-1842.2012.00984.x.

10. Vucovich LA, Gordon VS, Mitchell N, Ennis LA. Is the time and effort worth it? one library's evaluation of using social networking tools for outreach. Med Ref Serv Q. 2013; 32(1):12-25. doi: 10.1080/02763869.2013.749107.

11. Bardyn TP, Young CS. Migration to an electronic journal collection in a hospital library: implications for reference service. Med Ref Serv Q. 2007 Winter;26(4):27-44. doi: 10.1300/J115v26n04_03.

12. Thompson LL, Toedter LJ, D'Agostino FJ. Zero-based print journal collection development in a community teaching hospital library: planning for the future. J Med Libr Assoc. 2005 Oct;93(4):427-30.

13. Homan JM. Eyes on the prize: reflections on the impact of the evolving digital ecology on the librarian as expert intermediary and knowledge coach, 1969-2009. J Med Libr Assoc. 2010 Jan;98(1):49-56. doi: 10.3163/1536-5050.98.1.016.

14. Browne R, Lasserre K, McTaggart J, Bayley L, McKibbon A, Clark M, Perry GJ, Murphy J. International trends in health science librarianship: part 1 - the English speaking world. Health Info Libr J. 2012 Mar;29(1):75-80. doi: 10.1111/ j.1471-1842.2011.00973.x.

15. Murphy J. International trends in health science librarianship: part 7 taking stock. Health Info Libr J. 2013 Sep; 30(3):245-52. doi: 10.1111/hir.12034.

16. Marshall JG, Sollenberger J, Easterby-Gannett S, Morgan LK, Klem ML, Cavanaugh SK, Oliver KB, Thompson CA, Romanosky N, Hunter S. The value of library and information services in patient care: results of a multisite study. $J$ Med Libr Assoc. 2013 Jan;101(1):38-46. doi: 10.3163/1536-5050. 101.1.007.

17. Bartlett JC, Marshall JG. Gard. The value of library and information services in patient care: Canadian results from an international multisite study. J Can Health Libr Assoc. 2013;34(3):138-46. doi: 10.5596/c13-063.

18. Davidoff F, Florance V. The informationist: a new health profession? Ann Intern Med. 2000 Jun 20;132(12):996-8. doi: 10.7326/0003-4819-132-12-200006200-00012.

19. Grefsheim SF, Whitmore SC, Rapp BA, Rankin JA, Robison RR, Canto CC. The informationist: building evidence for an emerging health profession. J Med Libr Assoc. 2010 Apr;98(2):147-56. doi: 10.3163/1536-5050.98.2.007.

20. Flynn MG, McGuinness C. Hospital clinicians' information behaviour and attitudes towards the 'clinical informationist': an Irish survey. Health Info Libr J. 2011 Mar;28(1):23-32. doi: 10.1111/j.1471-1842.2010.00917.x.
21. Tan MC, Maggio LA. Expert searcher, teacher, content manager, and patient advocate: an exploratory study of clinical librarian roles. J Med Libr Assoc. 2013 Jan;101(1): 63-72. doi: 10.3163/1536-5050.101.1.010.

22. Cooper ID, Crum JA. New activities and changing roles of health sciences librarians: a systematic review, 1990-2012. J Med Libr Assoc. 2013 Oct;101(4):268-77. doi: 10.3163/15365050.101.4.008.

23. Bandy M, Condon J, Graves E. Participating in communities of practice. Med Ref Serv Q. 2008 Winter;27(4):441-9. doi: 10.1080/02763860802368316.

24. Wu L, Mi M. Sustaining librarian vitality: embedded librarianship model for health sciences libraries. Med Ref Serv Q. 2013;32(3):257-65. doi: 10.1080/02763869.2013. 806860 .

25. Tooey MJ. A pathway for hospital librarians: why is it vital? J Med Libr Assoc. 2009 Oct;97(4):268-72. doi: 10.3163/15365050.97.4.010.

26. Holst R, Funk CJ, Adams HS, Bandy M, Boss CM, Hill B, Joseph CB, Lett RK. Vital pathways for hospital librarians: present and future roles. $J$ Med Libr Assoc. 2009 Oct;97(4):285-92. doi: 10.3163/1536-5050.97.4.013.

27. Medical Library Association. Benchmarking Data Worksheet. [Internet]. Chicago, IL: Medical Library Association; 2007 [cited 2014 Nov 20]. Available from: https://www. mlanet.org/resources/bench07/worksheet.html.

28. HLWIKI Canada contributors. List of Canadian health libraries. [Internet]. [cited 1 Dec 2014]. Available from: http://hlwiki.slais.ubc.ca/index.php?title=List_of_Canadian_ health_libraries\&oldid $=133392$.

29. Grey House Publishing Canada. Libraries Canada. Toronto, ON: Grey House; 2009.

30. Bandy M, Doyle JD, Fladger A, Frumento KS, Girouard L, Hayes S, Rourke D. Standards for hospital libraries 2007. J Med Libr Assoc. 2008 Apr;96(2):162-9.

31. Starr S. Moving from evaluation to assessment. J Med Libr Assoc. 2014 Oct;102(4):227-9. doi: 10.3163/1536-5050.102. 4.001 .

32. Shipman JP, Stoddart JM, Peay WJ. Building projects: redefining hospital libraries. J Med Libr Assoc. 2012 Jul; 100(3):166-70. doi: 10.3163/1536-5050.100.3.005.

33. Health Science Information Consortium of Toronto. Hospital library and information services: scope of practice. [Internet]. Toronto: Health Science Information Consortium of Toronto; 2014. [cited 2014 Dec 1]. Available from: http://lgdata.s3website-us-east-1.amazonaws.com/docs/3923/1090198/Hospital_ Library_Scope_of_Practice_HSICT_April_2014.pdf. 